\title{
Biomolecule-assisted synthesis of carbon nitride and sulfur-doped carbon nitride heterojunction nanosheets: An efficient heterojunction photocatalyst for photoelectrochemical applications
}

\author{
Hua Bing Tao, Hong Bin Yang ${ }^{*}$ Jiazang Chen, Jianwei Miao and Bin Liu*
}

\author{
Full Research Paper \\ Address: \\ School of Chemical and Biomedical Engineering, Nanyang \\ Technological University, 62 Nanyang Drive, Singapore 637459, \\ Singapore \\ Email: \\ Hong Bin Yang* - hbyang@ntu.edu.sg; Bin Liu* - liubin@ntu.edu.sg \\ * Corresponding author \\ Keywords: \\ graphitic carbon nitride $\left(\mathrm{g}-\mathrm{C}_{3} \mathrm{~N}_{4}\right)$; heterojunction; \\ photoelectrochemical; photocatalysis; sulfur doping
}

\begin{abstract}
A biomolecule-assisted pyrolysis method has been developed to synthesize sulfur-doped graphitic carbon nitride (CNS) nanosheets. During the synthesis, sulfur could be introduced as a dopant into the lattice of carbon nitride (CN). Sulfur doping changed the texture as well as relative band positions of $\mathrm{CN}$. By growing $\mathrm{CN}$ on preformed sulfur-doped $\mathrm{CN}$ nanosheets, composite $\mathrm{CN} / \mathrm{CNS}$ heterojunction nanosheets were constructed, which significantly enhanced the photoelectrochemical performance as compared with various control counterparts including $\mathrm{CN}$, CNS and physically mixed $\mathrm{CN}$ and $\mathrm{CNS}$ (CN+CNS). The enhanced photoelectrochemical performance of $\mathrm{CN} / \mathrm{CNS}$ heterojunction nanosheets could be ascribed to the efficient separation of photoexcited charge carriers across the heterojunction interface. The strategy of designing and preparing CN/CNS heterojunction photocatalysts in this work can open up new directions for the construction of all CN-based heterojunction photocatalysts.
\end{abstract}

\section{Introduction}

Over the past few years, graphitic carbon nitride $(\mathrm{CN})$ has attracted significant research attention in visible-light-driven photocatalysis because of its unique physical and chemical properties including chemical and thermal stability, physical abundance, as well as suitable bandgap energy and band position [1-4]. The polymeric nature of $\mathrm{CN}$ could facilitate the

tuning of the physical and chemical properties by simply changing the $\mathrm{CN}$ precursors, by varying the pyrolysis conditions and by doping with foreign atoms [5-8]. However, the photocatalytic performance of $\mathrm{CN}$ is still limited because of the fast charge recombination [6,8-10]. How to efficiently separate photogenerated charge carriers in $\mathrm{CN}$ becomes a critical factor 
in further improving the photocatalytic performance. The construction of heterojunctions is a simple and effective way to enhance charge carrier separation, in which the build-in electric field across the junction could drive electrons and holes moving towards different parts of the photocatalyst, and thus improving the lifetime of charge carriers [11]. Numerous CN-based heterojunctions have been constructed by coupling $\mathrm{CN}$ with various types of photocatalysts, e.g., oxides and chalcogenides, which have shown improved photocatalytic performances [12-18] However, the formation of interfacial defects at the $\mathrm{CN} /$ photocatalyst heterojunction arising from lattice mismatches would trap photogenerated electrons or holes, which reduces the benefits of build-in electric field created from the heterojunction. A smooth transition from one crystal phase to the other in a heterojunction could minimize the formation of interfacial defects, thus benefiting the interfacial charge transfer [19]. The formation of a smooth crystal transition would be expected at the interface of an all $\mathrm{CN}$-based heterojunction. However, it is still challenging to synthesize a composite $\mathrm{CN}$ photocatalyst which is solely based on $\mathrm{CN}$ with different band structures [20].

Herein, we employ a biomolecule-assisted (L-cysteine) pyrolysis method to synthesize sulfur-doped carbon nitride (CNS) nanosheets, which can serve as the framework to grow $\mathrm{CN}$ to form an all $\mathrm{CN}$-based heterojunction composite. The formation of $\mathrm{CN} / \mathrm{CNS}$ heterojunctions significantly improves the photoelectrochemical performance, which is attributed to the efficient separation of photoexcited charge carriers across the heterojunction interface. The strategy of designing and preparing $\mathrm{CN} / \mathrm{CNS}$ heterojunction photocatalysts in this work can open up new directions for the construction of all $\mathrm{CN}$-based heterojunction photocatalysts.

\section{Results and Discussion}

Figure $1 \mathrm{a}$ and Figure $1 \mathrm{~b}$ show the FESEM images of as-prepared $\mathrm{CN}$ and $\mathrm{CNS}$. CN is composed of large micrometer-sized particles, whereas CNS consists of small pieces of thin nanosheets, which are loosely connected with each other. Transmission electron microscopy gives a deeper insight into the crystal structure and morphology. As shown in Figure 1c and Figure 1d, in stark contrast with CN, CNS nanosheets are much smaller and thinner with worm-like nanopores dispersed on the surface of the nanosheets, owing predominantly to the drastic decomposition/delamination of CNS at high temperature. X-ray photoelectron spectroscopy (XPS) measurements were performed to study the chemical states of $\mathrm{CN}$ and $\mathrm{CNS}$. As shown in the survey spectra in Figure 1e, CN has the typical $\mathrm{C} 1 \mathrm{~s}$ and N1s signals, which evidence the successful formation of $\mathrm{CN}$ through thermal decomposition and polymerization of the amine precursor. Besides $\mathrm{C} 1 \mathrm{~s}$ and N1s signals, an additional S2p signal is observed in CNS. The atomic concentra- tion of sulfur in CNS is determined to be about 0.36 atom \%. The high-resolution S2p spectrum of CNS deconvolutes into two peaks centered at 163.5 and $168.2 \mathrm{eV}$, which could be ascribed to $\mathrm{S}-(\mathrm{C})_{3}$ (tertiary sulfur) and $\mathrm{C}-\mathrm{S}(\mathrm{O})-\mathrm{C}$ (secondary sulfur), respectively, providing a compelling evidence of sulfur doping (sulfur is introduced into $\mathrm{CN}$ through substituting lattice nitrogen with sulfur on both tertiary and secondary nitrogen sites) [21]. The higher intensity for the peak centered at $163.5 \mathrm{eV}$ than for that at $168.2 \mathrm{eV}$ suggests that the replacement of the secondary nitrogen with sulfur in $\mathrm{CN}$ is more favorable.

The effects of sulfur doping on the optical and energy band structure were investigated by UV-vis absorption and Mott-Schottky measurements. Figure 2a shows the UV-vis diffuse reflectance spectra of $\mathrm{CN}$ and CNS. Both $\mathrm{CN}$ and CNS feature a semiconductor-like absorption. The abrupt absorption onset for $\mathrm{CN}$ and CNS at ca. $450 \mathrm{~nm}$ is due to the photoexcitation of electrons from the valence band to the conduction band. The tail absorption in the long wavelength region for CNS could be attributed to the interband transition induced by defects through sulfur doping. The bandgap energy $\left(E_{\mathrm{g}}\right)$ estimated from the $(\alpha h v)^{2}$ versus $h v$ plots are 2.79 and $2.82 \mathrm{eV}$ for $\mathrm{CN}$ and CNS, respectively. Mott-Schottky measurements were conducted to estimate the relative conduction band position. From the intersects of the Mott-Schottky plots, the flatband potential and thus the conduction band edge of $\mathrm{CN}$ and $\mathrm{CNS}$ are estimated to be about -1.22 and $-1.01 \mathrm{eV}$ vs $\mathrm{Ag} / \mathrm{AgCl}$, respectively. Together with the bandgap energy obtained from optical absorption measurements, the valence band position for $\mathrm{CN}$ and CNS are estimated to be about 1.57 and $1.81 \mathrm{eV}$ vs $\mathrm{Ag} / \mathrm{AgCl}$.

Based on the above analysis, it is clear that $\mathrm{CN}$ can form a typeII heterojunction upon CNS with band offsets of $0.24 \mathrm{eV}$ $(1.57 \mathrm{eV} / 1.81 \mathrm{eV}$ vs $\mathrm{Ag} / \mathrm{AgCl})$ and $0.21 \mathrm{eV}(-1.22 \mathrm{eV} /-1.01 \mathrm{eV}$ vs $\mathrm{Ag} / \mathrm{AgCl})$ at the valence and conduction band, respectively (Figure 3a). This type-II band alignment means that once $\mathrm{CN}$ and CNS are electronically coupled, a well-matched band structure for charge separation will be formed. In this case, the photogenerated electrons are transferred from $\mathrm{CN}$ to $\mathrm{CNS}$, while the photogenerated holes are transferred from CNS to $\mathrm{CN}$, leading to an improved charge separation. To test our hypothesis, we designed a strategy to construct $\mathrm{CN} / \mathrm{CNS}$ heterostructures. In our method, we firstly grow CNS nanosheets by using a biomolecule-assisted pyrolysis method, followed by growing $\mathrm{CN}$ on preformed $\mathrm{CNS}$ nanosheets to form a well-mixed CN/CNS heterostructure.

Figure 4a shows the FESEM image of a CN/CNS composite heterostructure. In comparison with CNS (Figure 1b), the framework of CNS was well preserved after $\mathrm{CN}$ growth, while 

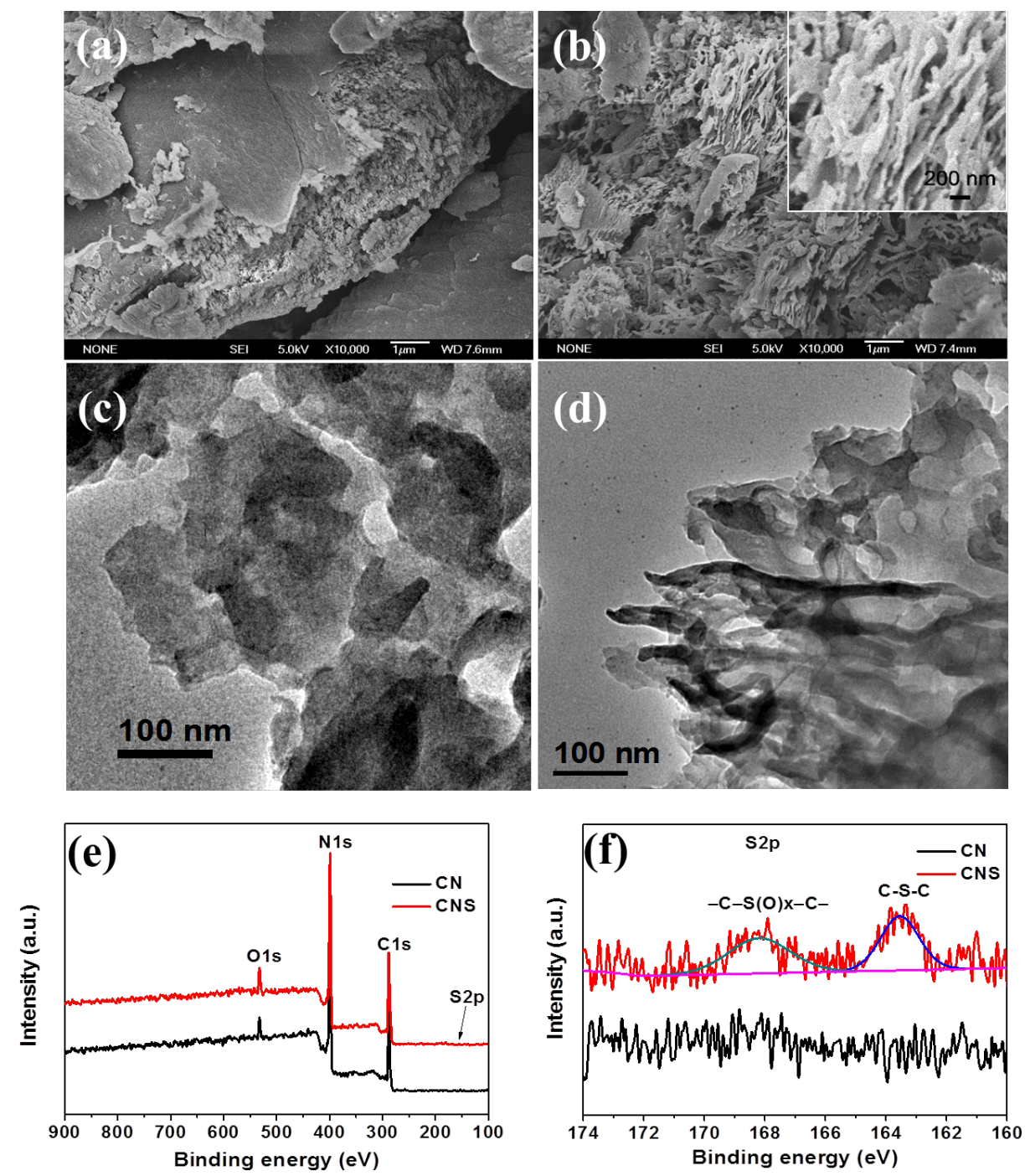

Figure 1: FESEM and TEM images of $(a, c) C N$, and $(b, d) C N S$ samples. The inset of $(b)$ is an enlarged FESEM image of the CNS sample. (e,f) Survey XPS spectra and high-resolution S2p XPS spectra of CN and CNS samples.
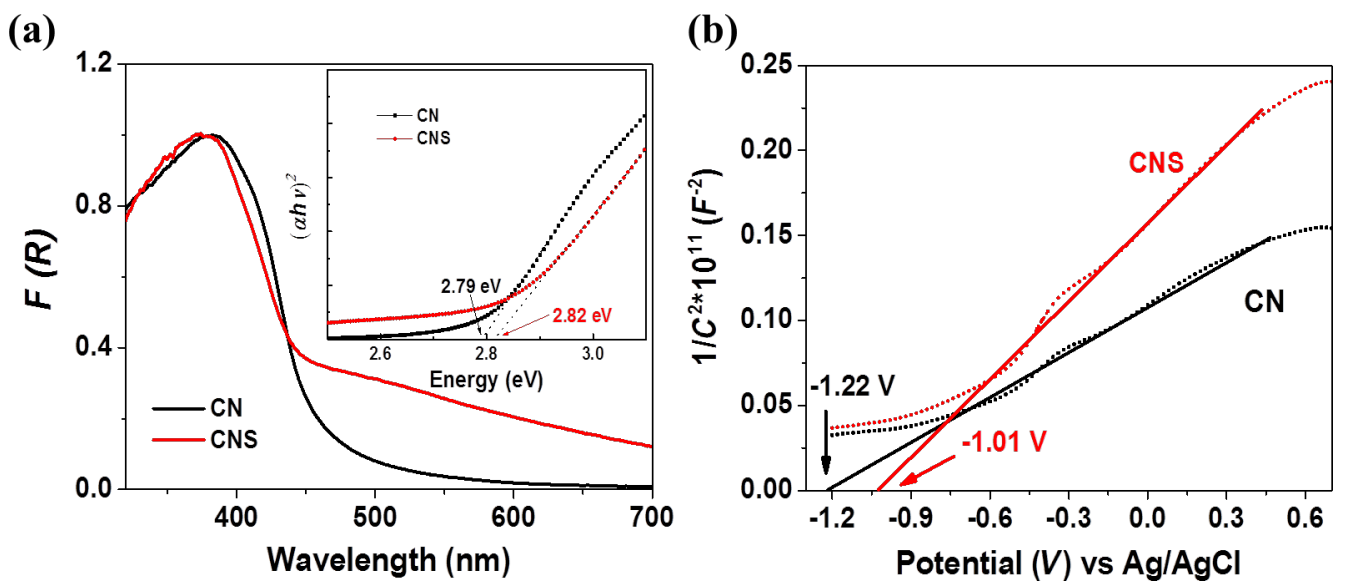

Figure 2: (a) Optical absorption spectra of $\mathrm{CN}$ and $\mathrm{CNS}$. Inset shows the Tauc plots for bandgap determination, (b) Mott-Schottky plots for $\mathrm{CN}$ and CNS. 
(a)

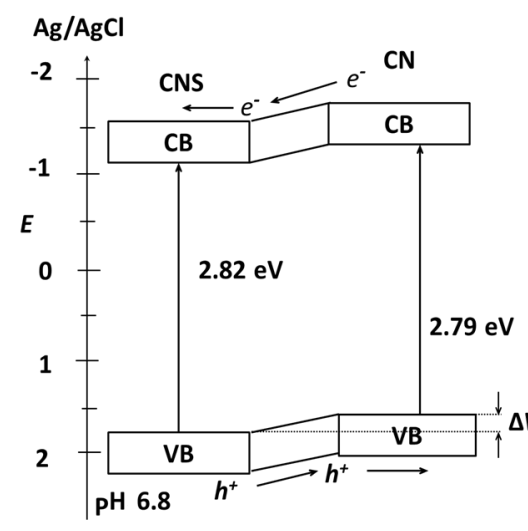

(b)

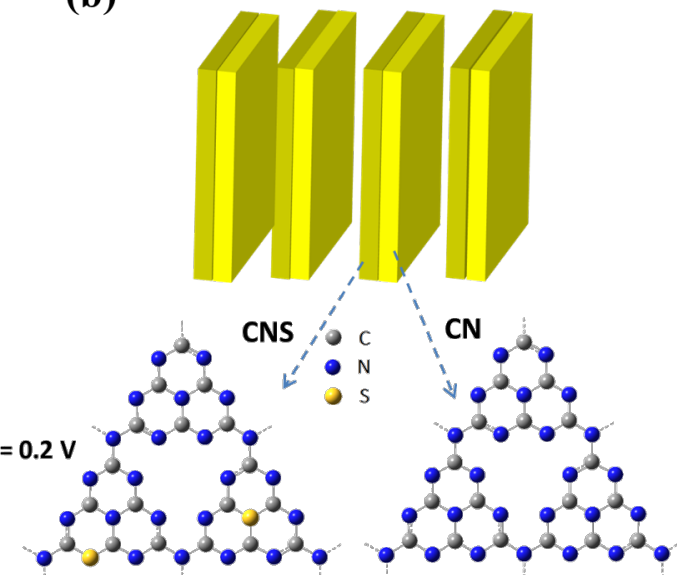

Figure 3: Schematic illustration of (a) electron-hole separation at the CN/CNS heterojunction interface, (b) the structure of CN/CNS heterojunction.

the thickness of nanosheets increased from ca. $30 \mathrm{~nm}$ for CNS to ca. $50 \mathrm{~nm}$ for $\mathrm{CN} / \mathrm{CNS}$ composite. Figure $4 \mathrm{~b}$ shows the XRD patterns of $\mathrm{CN}$, CNS and the $\mathrm{CN} / \mathrm{CNS}$ heterojunction composite. Two diffraction peaks are clearly visible in all XRD patterns. The peak centered at $13^{\circ}$ could be indexed to the (100) plane of $\mathrm{CN}$, corresponding to the in-plane structural packing motif of tristriazine unit. The peak was slightly shifted towards a higher diffraction angle when sulfur was introduced into the $\mathrm{CN}$ lattice. The calculated hole-to-hole distances in the nitride pores of $\mathrm{CN}$ and CNS are 0.691 and $0.660 \mathrm{~nm}$, respectively. The other peak at $27.5^{\circ}$ could be assigned to the interlayer stacking of aromatic units, which is also noted as (002) plane. Analogous to the (100) peak, the (002) peak shifted from $27.2^{\circ}$ in $\mathrm{CN}$ to $27.7^{\circ}$ in $\mathrm{CNS}$, indicating a reduction of the inter-plane distance after sulfur doping. The calculated interlayer distances of $\mathrm{CN}$ and $\mathrm{CNS}$ are 0.327 and $0.322 \mathrm{~nm}$, respectively. The (002) peak of $\mathrm{CN} / \mathrm{CNS}$ becomes wider than that of $\mathrm{CN}$ and $\mathrm{CNS}$. A further analysis shows that the peak of $\mathrm{CN} / \mathrm{CNS}$ can be
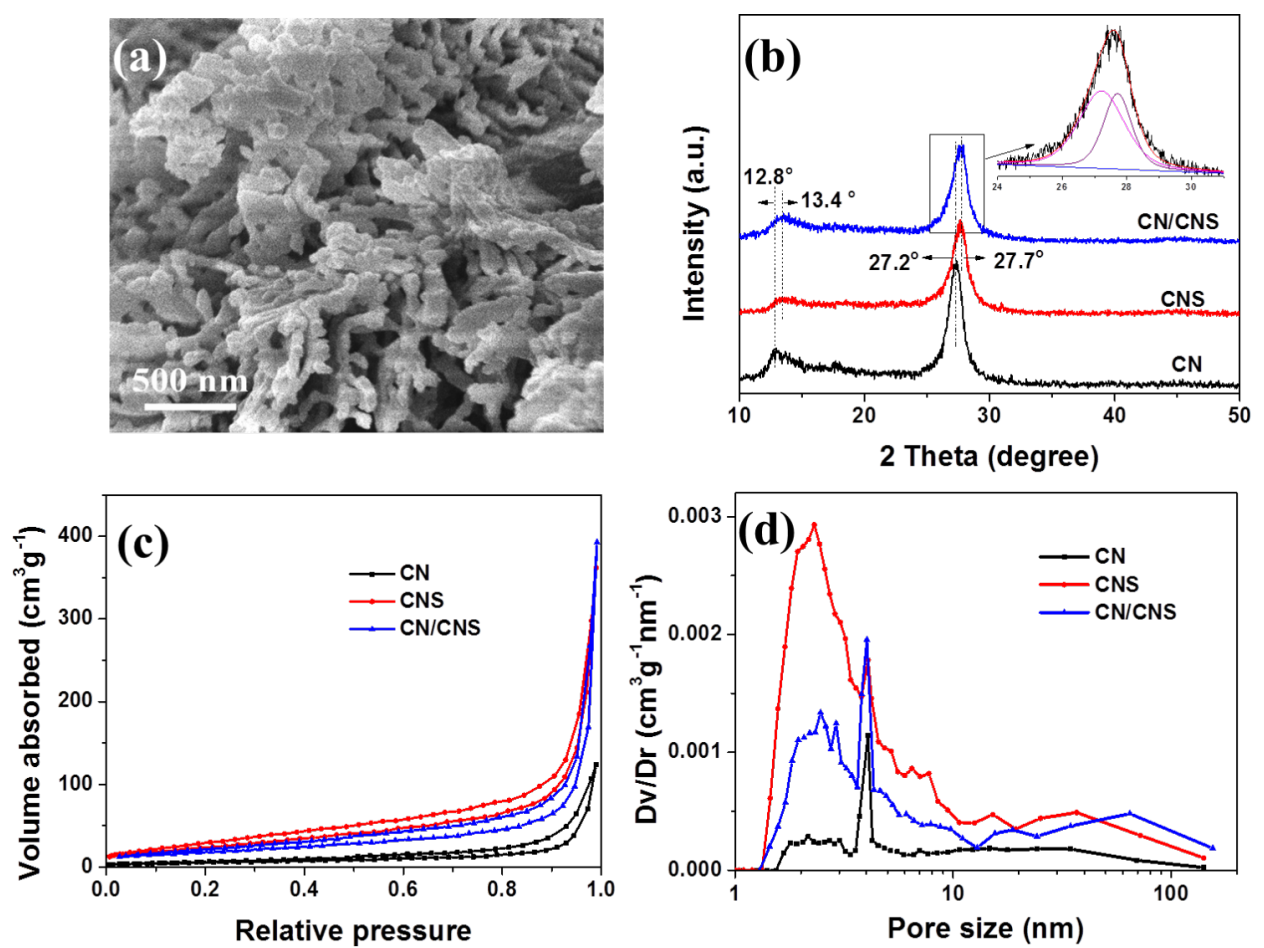

Figure 4: (a) FESEM image of CN/CNS heterostructure, (b) XRD and (c) nitrogen adsorption-desorption isotherms and (d) pore size distribution (insert) of $\mathrm{CN}, \mathrm{CNS}$ and $\mathrm{CN} / \mathrm{CNS}$ heterostructure. 
split into two peaks at $27.2^{\circ}$ and $27.7^{\circ}$, corresponding to the (002) peaks of $\mathrm{CN}$ and $\mathrm{CNS}$, respectively. The composite peak of $\mathrm{CN} / \mathrm{CNS}$ indicates that $\mathrm{CN} / \mathrm{CNS}$ is a hybrid of $\mathrm{CN}$ and $\mathrm{CNS}$, confirming the formation of a $\mathrm{CN} / \mathrm{CNS}$ heterostructure. Nitrogen adsorption-desorption analysis in Figure $4 \mathrm{c}$ confirmed the significant change of the $\mathrm{CN}$ texture after sulfur doping. The specific surface area for $\mathrm{CN}$ and CNS are 21 and $118 \mathrm{~cm}^{2} \cdot \mathrm{mg}^{-1}$, respectively. The surface area of the $\mathrm{CN} / \mathrm{CNS}$ heterostructure (about $56 \mathrm{~cm}^{2} \cdot \mathrm{mg}^{-1}$ ) is reduced to about half of that of CNS due to increased thickness of nanosheets. Figure $4 \mathrm{~d}$ presents the pore size distribution of $\mathrm{CN}, \mathrm{CNS}$ and the $\mathrm{CN} / \mathrm{CNS}$ heterostructure. It is clear that sulfur doping significantly increases the pore volume of micro- (smaller than $10 \mathrm{~nm}$ ) and meso- (larger than $100 \mathrm{~nm}$ ) pores, which could favor the photocatalytic performance [22].

Figure 5 shows the TEM image of CN/CNS heterostructure. As shown in Figure 5a, a layered structure made up of a dark region and a dim region can be clearly distinguished. The dark and $\operatorname{dim}$ region can be ascribed to dense $\mathrm{CN}$ and $\mathrm{CNS}$ nanosheets, respectively, based on the high-resolution TEM (HRTEM) analysis as shown in Figure 5b. Furthermore, it can be observed that the dense $\mathrm{CN}$ layer intimately connects with the CNS nanosheet to form a heterostructure. The HRTEM image of CN/CNS as shown in Figure 5b clearly distinguishes the phases of $\mathrm{CN}$ (the dark region) and CNS (the dim region). The lattice spacing for the dark region and the dim region are $0.328 \mathrm{~nm}$ and $0.322 \mathrm{~nm}$ respectively, which are consistent with the XRD results. The HRTEM image gives solid evidence towards the formation of heterojunction in $\mathrm{CN} / \mathrm{CNS}$.

Figure 6a shows the photoluminescence (PL) spectra of $\mathrm{CN}$, $\mathrm{CNS}$ and a $\mathrm{CN} / \mathrm{CNS}$ heterostructure. In comparison with $\mathrm{CN}$ and CNS, a substantial reduction in PL intensity was observed for the hybrid $\mathrm{CN} / \mathrm{CNS}$ heterostructure, suggesting an efficient charge carrier separation at the $\mathrm{CN} / \mathrm{CNS}$ interface. Linear sweep photovoltammetry measurements were performed to study the photoelectrochemical performances of $\mathrm{CN}, \mathrm{CNS}$ and the $\mathrm{CN}$ / CNS heterostructure. As shown in Figure 6b, photocurrent densities of the samples increase with forward bias voltage, indicating a typical n-type semiconductor behavior. Among all samples, the CN/CNS heterostructure demonstrates the highest photocurrent as compared with the other counterparts including $\mathrm{CN}$, CNS and physically mixed $\mathrm{CN}$ and CNS over the entire potential profile. It is worth noting that the dark current densities of the photoelectrodes follow the order of $\mathrm{CN} / \mathrm{CNS}$ heterostructure $>\mathrm{CNS}>\mathrm{CN}$, indicating the best charge transport properties of $\mathrm{CN} / \mathrm{CNS}$ photoelectrode, which can be attributed to the large contact area between the CN/CNS photoelectrode and the electrolyte as well as an appropriate band alignment of the CN/CNS interface. It has been well-established that photocurrent is generated because of the diffusion of photogenerated electrons to the back contact and the simultaneous consumption of photogenerated holes by the hole acceptor in the electrolyte. As such, the superior photocurrent of CN/CNS heterostructure indicates the more efficient charge carrier separation and longer lifetime of the free charge carriers. A control experiment using physically mixed $\mathrm{CN}$ and CNS (1:1 in mass, named as $\mathrm{CN}+\mathrm{CNS}$ ) as photoelectrode was preformed (UV-vis and $J-V$ curves are shown in Figure S1a and Figure S1b, respectively). Although the absorption of physically mixed $\mathrm{CN}$ and CNS is nearly the same as that of the CN/CNS heterojunction sample, the photocurrent of $\mathrm{CN}+\mathrm{CNS}$ is much lower, implying that the enhanced photoresponse of heterojunction sample comes from better separation of photogenerated electrons and holes instead of improved photon absorption. The mechanism
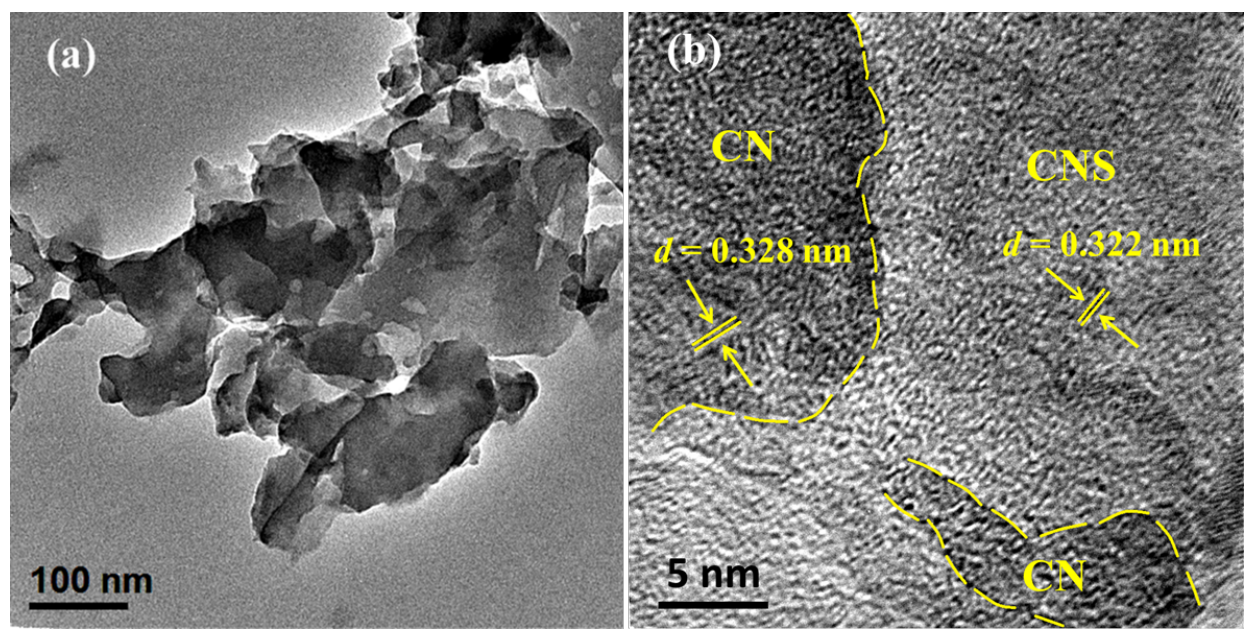

Figure 5: TEM (a) and HRTEM (b) images of a CN/CNS heterostructure. 
(a)
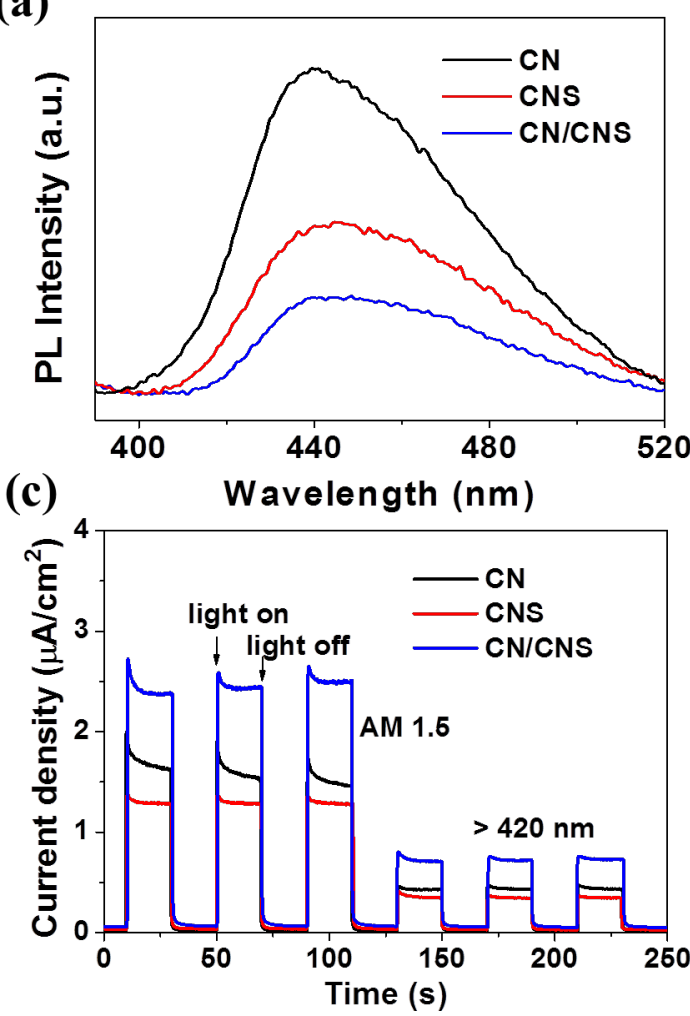
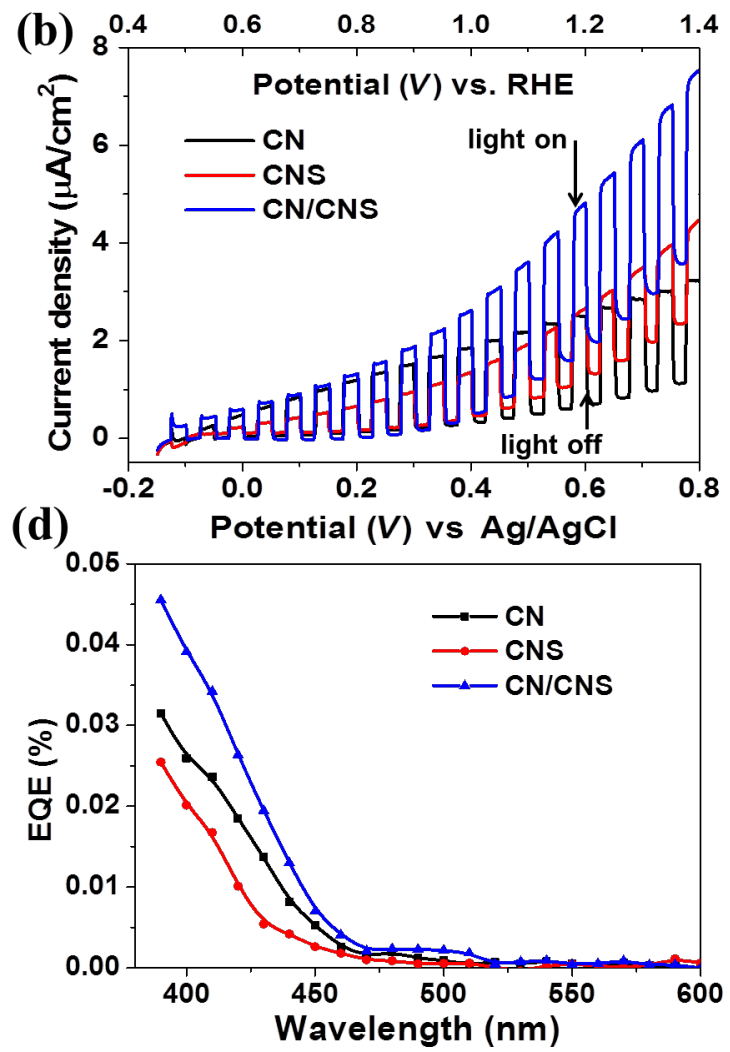

Figure 6: (a) Photoluminescence of CN, CNS and CN/CNS in aqueous solution. (b) Current density-voltage ( $\mathrm{J}-\mathrm{V}$ ) curves for CN, CNS and CN/CNS electrodes under simulated sunlight (AM 1.5, $\left.100 \mathrm{~mW} / \mathrm{cm}^{2}\right)$. All experiments were performed in $0.2 \mathrm{M} \mathrm{Na}_{2} \mathrm{SO}_{4}$ aqueous solution at a scan rate of $10 \mathrm{mV} / \mathrm{s}$. (c) Current density-time $(\mathrm{J}-t)$ curves for $\mathrm{CN}$, CNS and CN/CNS electrodes with $0.4 \mathrm{~V}$ bias vs $\mathrm{Ag} / \mathrm{AgCl}$ under simulated sunlight (AM 1.5 , $\left.100 \mathrm{~mW} / \mathrm{cm}^{2}\right)$ and visible light $(\lambda>420 \mathrm{~nm})$. (d) External quantum efficiency (EQE) of CN, CNS and CN/CNS photoelectrodes.

for photocurrent enhancement was further studied by measuring the photoresponse under different light source and the EQE spectra. Figure $6 \mathrm{c}$ exhibits the photoresponse of $\mathrm{CN}, \mathrm{CNS}$ and $\mathrm{CN} / \mathrm{CNS}$ under different light sources. It can be observed that the photocurrent can be reproducibly produced under AM $1.5 \mathrm{G}$ simulated sunlight or visible light $(\lambda>420 \mathrm{~nm})$ with the same trend following the order of $\mathrm{CN} / \mathrm{CNS}$ heterostructure $>\mathrm{CN}>$ CNS. The low photocurrent density might be due to the poor contact among $\mathrm{CN}$ particles and FTO substrate. Figure 6d shows the external quantum efficiency (EQE) of $\mathrm{CN}, \mathrm{CNS}$ and the $\mathrm{CN} / \mathrm{CNS}$ heterostructure, which matches well with the corresponding photocurrent density. It is worth mentioning that the shape of the three EQE curves are similar with the same cut off at nearly $470 \mathrm{~nm}$, indicating that the enhanced photocurrent of $\mathrm{CN} / \mathrm{CNS}$ heterostructure mainly comes from improved charge separation at the $\mathrm{CN} / \mathrm{CNS}$ heterojunction interface.

\section{Conclusion}

In conclusion, we have developed a biomolecule-assisted pyrolysis method to synthesize sulfur doped carbon nitride nanosheets (CNS), which offers an effective way to modify the texture and energy band positions of carbon nitride $(\mathrm{CN})$. By growing $\mathrm{CN}$ on preformed sulfur-doped $\mathrm{CN}$ nanosheets, composite CN/CNS heterojunction nanosheets were constructed, which exhibited a significantly enhanced photoelectrochemical performance as compared with various control counterparts including $\mathrm{CN}$, CNS and physically mixed $\mathrm{CN}$ and $\mathrm{CNS}(\mathrm{CN}+\mathrm{CNS})$. The enhanced photoelectrochemical performance of $\mathrm{CN} / \mathrm{CNS}$ heterojunction nanosheets could be ascribed to the efficient separation of photoexcited charge carriers across the heterojunction interface. Our approach offers a facile way to construct an all carbon nitride based heterojunction photocatalyst.

\section{Experimental}

\section{Materials preparation}

Graphitic carbon nitride $(\mathrm{CN})$ was prepared according to a reported pyrolysis method [23]. Typically, $2 \mathrm{~g}$ of melamine powder was put into an alumina crucible covered with a piece of titanium sheet, then heated at a heating rate of $2.3{ }^{\circ} \mathrm{C} / \mathrm{min}$ to $550{ }^{\circ} \mathrm{C}$ in a tube furnace and maintained at this temperature for $4 \mathrm{~h}$ under flowing argon. To synthesize sulfur-doped carbon nitride (CNS), $222 \mathrm{mg}$ of L-cysteine was blended with $2 \mathrm{~g}$ of melamine in an agate mortar, wherein L-cysteine acts as the 
sulfur source for sulfur doping. During the pyrolysis process, the -SH functional group in L-cysteine reacts with the amine group in melamine to substitute the $\mathrm{N}$ atoms and to form the $\mathrm{S}-\mathrm{C}$ bond. Following, this mixture was heated to $550{ }^{\circ} \mathrm{C}$ at a heating rate of $2.3{ }^{\circ} \mathrm{C} / \mathrm{min}$ and maintained at this temperature for $2 \mathrm{~h}$. The $\mathrm{CN} / \mathrm{CNS}$ heterojunction was prepared through thermal condensation of melamine on preformed CNS nanosheets. Specifically, $1 \mathrm{~g}$ of melamine and $1 \mathrm{~g}$ of preformed CNS nanosheets were mixed together and underwent the same pyrolysis process as that for the preparation of CN. Physical mixtures of $\mathrm{CN}$ and $\mathrm{CNS}$ (1:1 mass ratio) were also prepared as reference.

\section{Characterization}

The morphology of the samples was examined by using field emission scanning electron microscopy (FESEM, JEOL, JSM6701F) and transmission electron microscopy (TEM, JEOL 3010). The chemical bonding information was studied with X-ray photoelectron spectroscopy (Kratos AXIS Ultra spectrometer) with a monochromatized Al Ka X-ray source $(1486.71 \mathrm{eV})$. The Brunauer-Emmett-Teller (BET) surface area of sample was obtained on a nitrogen adsorption apparatus (Autosorb-6B, Quantachrome Instruments) with all samples degassed at $150{ }^{\circ} \mathrm{C}$ for $16 \mathrm{~h}$ prior to the measurement. The UV-vis diffuse reflectance spectra (DRS) were obtained on a UV-vis spectrometer (ShimadzuUV2450) using $\mathrm{BaSO}_{4}$ as reference. The powder X-ray diffraction (XRD) patterns were obtained on a Bruker D2 diffractometer (Bruker AXS, $\lambda=0.15418 \mathrm{~nm}$ ). The chemical states and percentage of sulfur were measured by using X-ray photoelectron spectroscopy (XPS) on a VG Escalab 220i XL and the binding energies were calibrated by using the $\mathrm{C} 1 \mathrm{~s}$ peak at $285.0 \mathrm{eV}$. The photoluminescence (PL) spectra were recorded using an LP920-KS instrument from Edinburgh Instruments, equipped with a photomultiplier tube.

\section{Photoelectrochemical measurements}

The photoelectrochemical properties of as-prepared samples were measured by using an electrochemical workstation (CHI $760 \mathrm{E}, \mathrm{CH}$ Instrument Inc., USA) in a standard three-electrode setup with a Pt plate as the counter electrode and an $\mathrm{Ag} / \mathrm{AgCl}$ as the reference electrode. In all cases, $0.2 \mathrm{M} \mathrm{Na}_{2} \mathrm{SO}_{4}$ aqueous solution ( $\mathrm{pH}$ 6.8) was used as the electrolyte. Prior to each measurement, the electrolyte was deaerated by continuously purging nitrogen for $30 \mathrm{~min}$. The working electrode was prepared as the following: briefly, $10 \mathrm{mg}$ of as-prepared sample was suspended in $1 \mathrm{~mL}$ of isopropyl alcohol (IPA). Then, $50 \mu \mathrm{L}$ of the colloidal suspension $(10 \mathrm{mg} / \mathrm{mL})$ was dropcasted onto precleaned fluorine-doped tin oxide (FTO) substrate with a fixed area of $1 \mathrm{~cm}^{2}$. After coating, the film was dried at $70{ }^{\circ} \mathrm{C}$ in ambient atmosphere, followed by annealing at $350{ }^{\circ} \mathrm{C}$ for $1 \mathrm{~h}$ under argon to improve physical and electrical contact. The light source used for photoelectrochemical measurement was a $300 \mathrm{~W}$ xenon lamp (Newport, Oriel, 91160) equipped with an AM 1.5G filter (Newport, 81094) and a UV-filter (Newport, FSQ-GG420) (cut off: $420 \mathrm{~nm}$ ). Prior to each measurement, the light intensity was determined by a calibrated silicon photodiode. The external quantum efficiency (EQE) was measured under $+0.4 \mathrm{~V}$ external bias (three-electrode) condition. The monochromatic light was supplied by a xenon lamp (300 W, Oriel) illuminating through a monochromator (Newport) with a bandwidth of $5 \mathrm{~nm}$.

\section{Supporting Information}

\section{Supporting Information File 1}

Additional experimental data.

[http://www.beilstein-journals.org/bjnano/content/

supplementary/2190-4286-5-89-S1.pdf]

\section{Acknowledgements}

The authors acknowledge Nanyang Technological University and the Singapore-Berkeley Research Initiative for Sustainable Energy (SinBeRISE) for the financial support.

\section{References}

1. Wang, X.; Maeda, K.; Chen, X.; Takanabe, K.; Domen, K.; Hou, Y.; Fu, X.; Antonietti, M. J. Am. Chem. Soc. 2009, 131, 1680-1681. doi:10.1021/ja809307s

2. Wang, X.; Maeda, K.; Thomas, A.; Takanabe, K.; Xin, G.; Carlsson, J. M.; Domen, K.; Antonietti, M. Nat. Mater. 2009, 8, 76-80. doi:10.1038/nmat2317

3. Wang, X.; Chen, X.; Thomas, A.; Fu, X.; Antonietti, M. Adv. Mater. 2009, 21, 1609-1612. doi:10.1002/adma.200802627

4. Zhang, J.; Chen, X.; Takanabe, K.; Maeda, K.; Domen, K.; Epping, J. D.; Fu, X.; Antonietti, M.; Wang, X. Angew. Chem., Int. Ed. 2010, 49, 441-444. doi:10.1002/anie.200903886

5. Zhang, J.; Sun, J.; Maeda, K.; Domen, K.; Liu, P.; Antonietti, M.; Fu, X.; Wang, X. Energy Environ. Sci. 2011, 4, 675-678. doi:10.1039/c0ee00418a

6. Wang, Y.; Wang, X.; Antonietti, M. Angew. Chem., Int. Ed. 2012, 51, 68-89. doi:10.1002/anie.201101182

7. Wang, Y.; Li, H.; Yao, J.; Wang, X.; Antonietti, M. Chem. Sci. 2011, 2, 446-450. doi:10.1039/c0sc00475h

8. Dong, F.; Zhao, Z.; Xiong, T.; Ni, Z.; Zhang, W.; Sun, Y.; Ho, W.-K. ACS Appl. Mater. Interfaces 2013, 5, 11392-11401. doi:10.1021/am403653a

9. Wang, X.; Blechert, S.; Antonietti, M. ACS Catal. 2012, 2, 1596-1606. doi:10.1021/cs300240x

10. Zheng, Y.; Liu, J.; Liang, J.; Jaroniec, M.; Qiao, S. Z. Energy Environ. Sci. 2012, 5, 6717-6731. doi:10.1039/c2ee03479d

11. Marschall, R. Adv. Funct. Mater. 2014, 24, 2421-2440. doi:10.1002/adfm.201303214

12. Xiang, Q.; Yu, J.; Jaroniec, M. J. Phys. Chem. C 2011, 115, 7355-7363. doi:10.1021/jp200953k 
13. Yan, S. C.; Lv, S. B.; Li, Z. S.; Zou, Z. G. Dalton Trans. 2010, 39, 1488-1491. doi:10.1039/b914110c

14. Sun, J.-X.; Yuan, Y.-P.; Qiu, L.-G.; Jiang, X.; Xie, A.-J.; Shen, Y.-H.; Zhu, J.-F. Dalton Trans. 2012, 41, 6756-6763. doi:10.1039/c2dt12474b

15. Sun, L.; Qi, Y.; Jia, C.-J.; Jin, Z.; Fan, W. Nanoscale 2014, 6, 2649-2659. doi:10.1039/C3NR06104C

16. Wang, Y.; Bai, X.; Pan, C.; He, J.; Zhu, Y. J. Mater. Chem. 2012, 22 , 11568-11573. doi:10.1039/c2jm16873a

17. Fu, J.; Chang, B.; Tian, Y.; Xi, F.; Dong, X. J. Mater. Chem. A 2013, 1, 3083-3090. doi:10.1039/c2ta00672c

18. Zhang, J.; Wang, Y.; Jin, J.; Zhang, J.; Lin, Z.; Huang, F.; Yu, J. ACS Appl. Mater. Interfaces 2013, 5, 10317-10324. doi:10.1021/am403327g

19. Liu, B.; Khare, A.; Aydil, E. S. ACS Appl. Mater. Interfaces 2011, 3, 4444-4450. doi:10.1021/am201123u

20. Zhang, J.; Zhang, M.; Sun, R.-Q.; Wang, X. Angew. Chem., Int. Ed. 2012, 51, 10145-10149. doi:10.1002/anie.201205333

21. Liu, G.; Niu, P.; Sun, C.; Smith, S. C.; Chen, Z.; Lu, G. Q.; Cheng, H.-M. J. Am. Chem. Soc. 2010, 132, 11642-11648. doi:10.1021/ja103798k

22. Liu, B.; Zeng, H. C. Chem. Mater. 2008, 20, 2711-2718. doi: $10.1021 / \mathrm{cm} 800040 \mathrm{k}$

23. Yan, S. C.; Li, Z. S.; Zou, Z. G. Langmuir 2009, 25, 10397-10401. doi:10.1021/la900923z

\section{License and Terms}

This is an Open Access article under the terms of the Creative Commons Attribution License (http://creativecommons.org/licenses/by/2.0), which permits unrestricted use, distribution, and reproduction in any medium, provided the original work is properly cited.

The license is subject to the Beilstein Journal of Nanotechnology terms and conditions: (http://www.beilstein-journals.org/bjnano)

The definitive version of this article is the electronic one which can be found at: $\underline{\text { doi:10.3762/bjnano.5.89 }}$ 